\title{
Chronic airflow obstruction
}

\author{
DUNCAN M. GEDDES \\ M.A., M.D., F.R.C.P. \\ Brompton Hospital, London SW3
}

Chronic airflow obstruction (CAO) affects at least half a million people (Royal College of Physicians, 1981 ) in this country and will continue to be a major cause of morbidity and early death for many years to come. Even if cigarette smoking stopped today its legacy in CAO would continue beyond the end of the century. While acute respiratory infections, respiratory failure, cor pulmonale and death are the most dramatic manifestations, the major impact of the condition is in causing long-term disability through breathlessness. A man with severe CAO often has a grossly impaired quality of life for many years before he ever consults a doctor and eventually becomes virtually immobile and housebound.

The breathlessness and immobility of CAO is the result of a complex interaction of many factors. Airflow limitation on exercise reduces the maximum ventilation that can be achieved and is central to the sensation of breathlessness. However, cardiovascular function, the performance of skeletal muscle, (respiratory and non-respiratory), mood, personality and motivation all modify the sensation and also contribute independently to disability.

This article sets out to explore some of the factors involved in the breathlessness of CAO and how they may point the way to future treatments. The sensation of breathlessness itself and the mechanisms involved have been well reviewed in the past (Howell, 1966; Guz, 1977) and are beyond the scope of this article.

\section{Measurement}

\section{Lung function tests}

The traditional way of assessing patients with CAO has been to measure lung function at rest and while this provides valuable information about mechanics and gas exchange, it does not attempt to assess exercise tolerance. Forced expired volume in 1 sec $\left(F E V_{1}\right)$, vital capacity (VC), carbon monoxide diffusion capacity (DLCO) or coefficient (KCO) are usually measured and the way these correlate with exercise performance will be discussed below. In order to explore the relationship between lung function and mobility some objective, reproduciblo measure of breathlessness or disability is essential. 3 .

\section{Exercise testing}

Conventional exercise tests. Most lung functio laboratories which offer an exercise testing service use methods developed for the exacting requirements of exercise physiologists (Spiro, 1977). This results in a somewhat complex protocol which generates a lot of data and may not be ideal for assessing seriouslp disabled patients. Conventionally a cycle ergometer or exercise treadmill is used and the subject breathese through a mouth piece while he exercises. The work rate is increased at regular intervals until exhaustop (the progressive test) but may be maintained at constant work load, usually a certain percentage of previously determined maximum (the steady stat test). This form of exercise test gives a great deal of physiological information and can be very valuable in analysing the nature of a patient's exercise performance but is less satisfactory for quantifying his disability. This is because a cycle or treadmill is unfamiliar and very different from exercise encoun tered in day-to-day living, and because progressive exercise to exhaustion is quite unlike any normas activity. Furthermore, patients with CAO tolerate added respiratory loads with difficulty and so the effect of a mouthpiece with inspiratory and expiras tory resistance may, in itself, modify exercise pero formance.

Corridor walking distance. A much more simple approach was introduced by McGavin, Gupta and McHardy (1976) who pioneered the 12-min walking test. The patient is instructed to walk up and down a corridor so as to cover the maximum distance he can during $12 \mathrm{~min}$. He is encouraged during the test but is allowed to stop and rest whenever he needs. The distance he walks is a measure of his exercise tolerance. Surprisingly, this test is highly reproduci ble within individuals after two practices (coefficient of variation $4.3 \%$ ), and it has the considerable 
advantage that no equipment is required. The test can be performed simply in any hospital and the patient walks in his own normal way unencumbered by mouthpiece, nose clips etc. Recently the 12-min test has been compared with shorter periods and the results show that after practice patients walk at a constant speed and so the duration of the test is not critical (Butland et. al., 1982). A 6-min walk may be a good compromise between precision and convenience.

Scales of disability and breathlessness. The best known verbal assessments of breathlessness are the dyspnoea grade (Fletcher et al., 1959) and the oxygen cost diagram (Durwin and Passmore, 1967). These attempt to quantify breathlessness and disability in terms of everyday tasks and, while they provide a reasonable estimate, this is very imprecise and depends too much on the patient's memory and judgement which may be unreliable.

Grades of breathlessness (adapted from definitions of Fletcher et al., 1959)

Breathless at rest or on minimal effort

Able to walk about 100 yards $(91 \mathrm{~m})$ on the level

Able to walk for 1 mile $(1.6 \mathrm{~km})$ on the level at own pace but unable to keep up with people of similar age

Able to keep up with people of similar age on level but not on hills or stairs

Otherwise

The oxygen cost diagram (Fig. 1) is a form of visual analogue scale (VAS) and such scales have for some time been widely used for the measurement of mood, pain and other sensations (Bond and Lader, 1974). VAS have recently been applied to the more precise assessment of breathlessness. In essence the subject is shown a measured line (usually $10 \mathrm{~cm}$ ) anchored at each end by a verbal description of two extremes of a sensation and used in association with a single simple question, e.g.:

Not breathless How breathless are you now?

The subject marks the line at a point which best represents his breathlessness, and the distance along the line is then measured, so converting the sensation into a number. VAS can be used in two ways: either to assess a sensation at a single moment as in the example above, or to estimate a sensation or its effect in general or over a given period, e.g. how breathless have you been over the past week? Obviously the more vague the question and the longer the period referred to, the less reliable the estimate is likely to be.

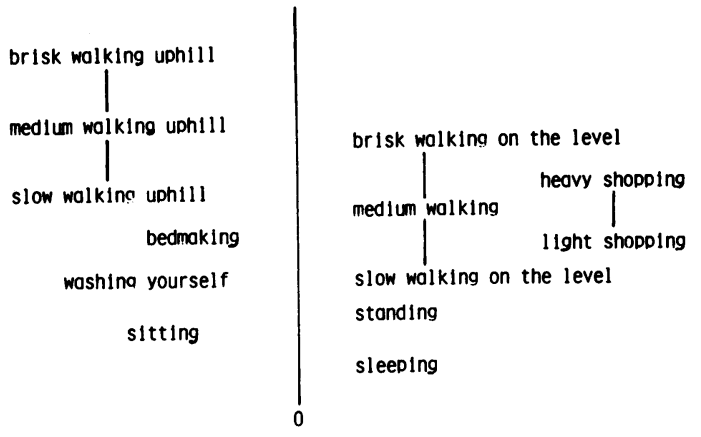

FIG. 1. Oxygen-cost diagram. Vertical line is normally $100 \mathrm{~mm}$ long, and everyday activities listed are placed proportionately to their oxygen cost. Patients were asked to indicate point above which they thought their breathlessness would not let them go.

The advantages of VAS are that they are simple to use and that they actually set out to measure breathlessness itself rather than its components, such as ventilation $\left(\dot{V}_{\mathrm{E}}\right)$, or its effects such as exercise tolerance. Studies in normal subjects have shown that breathlessness increases with ventilation but that the relationship is by no means simple (Guz et al., 1981; Stark, Gambles and Lewis, 1981). In the first place there is considerable inter-individual variation with some subjects recording breathlessness at low values of $\dot{V}_{E}$ while other reach high levels of $\dot{V}_{E}$ with only slight breathlessness. These differences may be partly related to fitness and body build but may also reflect psychological differences. Furthermore different ventilatory stimuli produce different amounts of breathlessness, for example the breathlessness from $\mathrm{CO}_{2}$ rebreathing is greater than from exercise for equivalent ventilation (Guz et al., 1981).

Similar studies by Woodcock (1982) in patients with CAO have shown:

(1) That patients can easily learn to use VAS during exercise.

(2) That the same inter-individual variation in breathlessness exists in patients as in normal.

(3) That the use of a face mask during exercise increases breathlessness.

(4) That VAS can be used to assess the value of treatment in CAO.

The place of VAS in the assessment of breathlessness in patients with lung disease is still uncertain. Breathlessness during exertion measured in this way correlates reasonably well with exercise tolerance when data from groups of patients are combined (see below). However, important differences between individuals may be lost when group data is averaged. This is well demonstrated in Fig. 2 where the effect of oxygen on breathlessness and exercise tolerance was being tested in a patient with CAO. The total 
distance walked when breathing oxygen or air is similar and suggests that oxygen is of no value. However the VAS of breathlessness score is very different for most levels of exercise. Experience of this sort suggests that VAS have a role in association with other simple tests of exercise tolerance.

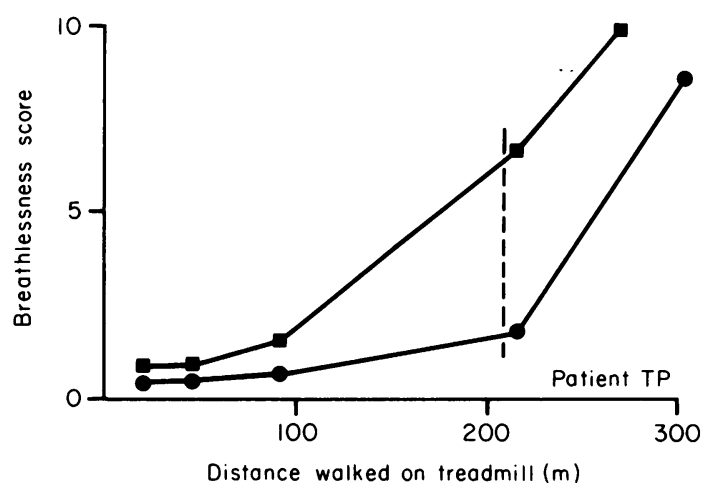

FIG. 2. Comparison of breathlessness during treadmill exercise breathing air carried by an assistant ( $\square$ ) and breathing oxygen carried by the patient (O).

Pedometer. All the measurements above focus on a patient's potential rather than actual disability. A pedometer can be used to measure simply how much exercise he actually performs during everyday life. The advantage of this in assessing therapy is obvious. The disadvantages are that pedometers are inaccurate, the patient may forget to wear or read the instrument, and the inability of the measurement to take into account the differences between walking on the flat and climbing hills or stairs. Nevertheless, a daily pedometer distance provides the only objective estimate of a patient's activity and this form of assessment merits wider use.

\section{Comparison between measurements}

Table 1 shows correlation coefficients between a 6min corridor walking distance and some of the measurements described above in patients with airflow obstruction. The findings of the Edinburgh group using the 12-min test (McGavin et al., 1978) are shown for comparison. The most interesting finding is that lung function tests at rest are only weakly correlated with exercise tolerance. The DLCO predicts exercise tolerance better than spirometric volumes presumably because the DLCO contains information about gas exchange as well as lung volume (DLCO $=\mathrm{VA} \times \mathrm{KCO})$, while the $\mathrm{VC}$, a relatively natural respiratory manoeuvre, seems to be better than the somewhat artificial FEV. However the rather low correlation coefficients suggest that these tests are measuring only some of the factors causing disability and we must look elsewhere to trĕ to explain much of the difference between individu als.

TABLE 1. Correlation coefficients between 6-min $(6 \mathrm{MD})$ and $\stackrel{\mathcal{G}}{9}$ 12-min (12 MD) walking distances, lung function and

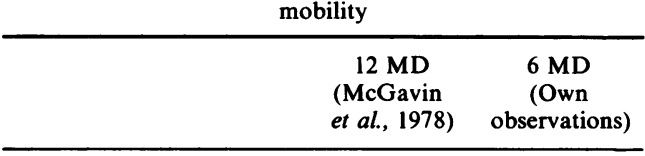

\begin{tabular}{lcl}
\hline Progressive exercise test & - & 0.82 \\
Visual analogue scale & - & 0.71 \\
MRC dyspnoea grade & 0.78 & 0.72 \\
Oxygen cost diagram & 0.60 & 0.63 \\
DLCO & - & 0.60 \\
FVC & 0.52 & 0.36 \\
FEV & 0.44 & 0.22 \\
\hline
\end{tabular}

\section{Correlations with psychological factors}

There is considerable evidence of excessive psy chiatric morbidity in patients with chronic lung disease and even some suggestions that specific personality types may respond to CAO in differen ways. Recently, the relationship between exercis: performance and different psychological measures has been explored independently by ourselves gnd McHardy's group in Edinburgh. Table 2 summarize? the chief findings.

TABLE 2. Correlation coefficients between walking distance and psychological measures in CAO

\begin{tabular}{lrr}
\hline & $\begin{array}{c}\text { 12-min walking } \\
\text { distance } \\
(n=50)\end{array}$ & $\begin{array}{c}\text { 6-min walking } \\
\text { distance } \\
(n=18)\end{array}$ \\
\hline FEV & 0.26 & 0.22 \\
FVC & 0.29 & 0.36 \\
Anxiety & -0.28 & -0.53 \\
Depression & -0.43 & -0.76 \\
\hline
\end{tabular}

The Edinburgh workers showed that the mosif important considerations were the patients' attitudes and beliefs. Those with a positive outlook who minimized their disease and had high hopes of successful treatment walked further than their more pessimistic colleagues. The apparently greater impor tance of anxiety and depression in the Londo patients probably reflects different referral patterns 0

It seems likely that vicious cycles become estabe lished in CAO with increasing disadvantage to the patient. The initial disability caused by breathlessness leads to depression, isolation and unfitness and each of these in their turn increase breathlessnes $\$$ and reduce the patient's mobility. This is illustrated in Fig. 3. 


\section{Conclusions}

(1) Standard lung function tests in CAO do not correlate well with exercise performance or measurements of breathlessness.

(2) Questionnaires or visual analogue scales can be used to assess breathlessness and give a good indication of disability.

(3) Exercise testing gives the most precise reproducible information and a simple corridor walking test is the best test for general use.

(4) Psychological factors are at least as important as lung function in determining a patient's disability.

\section{Treatment}

The aim of this section is to highlight recent work in the treatment of breathlessness rather than to provide a comprehensive review of the therapy of CAO. The role of antibiotics, physiotherapy, bronchodilators, corticosteroids, smoking withdrawal, weight loss, immunization, venesection, surgery of bullae, long-term oxygen, diuretics etc, will not, therefore, be considered further. It is however, important to emphasize the central position of all these measures which must be used to achieve the best possible lung and cardiac function before the treatments discussed below should be considered.

\section{Portable oxygen}

There are a large number of reports to show that patients with CAO benefit from portable oxygen (Cotes and Gilson, 1956; Lilbker, Kormick and Lerner, 1975; Raimondi, Edwards and Denison, 1980; Pierce, Paez and Miller, 1965; Bradley et al., 1978; Leggett and Flenley, 1977). This was first established by Cotes in 1956 and the conclusions of subsequent studies can be summarized as follows.
(1) Lung function tests, arterial blood gas tensions or the measurements of exercise physiology cannot be used to predict which patient will benefit.

(2) The amount of benefit is also unpredictable.

(3) The weight of the portable supply offsets much of the benefit.

(4) Oxygen breathing before short bursts of exercise can be helpful (Woodcock, Gross and Geddes, 1981a).

(5) There is no consensus about which patient to assess for portable oxygen, nor how to do the assessment.

Because of these difficulties and uncertainties, few patients at present use portable oxygen. The problems are made worse by the need to fill the portable unit from a large compressed oxygen cylinder which some patients find difficult or frightening, and by patients' embarrassment at using a mask or nasal cannulae in public.

All patients who are severely distressed or disabled by breathlessness should be assessed for the value of oxygen. The simple system shown in Table 3 is suggested. If the test is positive then portable oxygen should be supplied but initially for a trial period of 1 month only. This is because many patients who show objective benefit find the equipment too inconvenient in practice. It is worth explaining that oxygen both before and after bursts of exercise can be helpful and that a small two-wheeled trolley or shopping trolley to carry the oxygen is sometimes useful. A walking frame to which the oxygen is attached can be supplied for very breathless patients as it supplies shoulder girdle support which helps the accessory muscles of ventilation. An interested occupational therapist is invaluable.

Liquid oxygen has been tested for portable use but has advantages only for those who are being treated with continuous oxygen. The liquid oxygen unit can be used for up to $8 \mathrm{hr}$ while the portable cylinder lasts

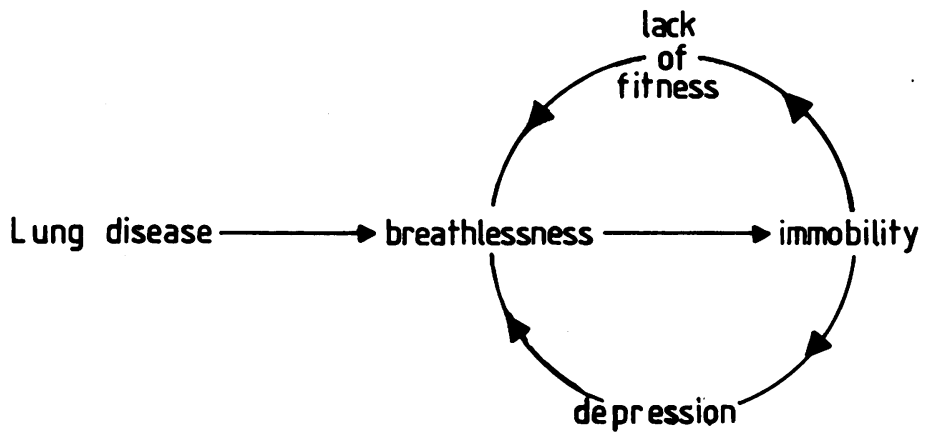

FIG. 3. Vicious cycles in lung disease. 
TABLE 3. The assessment of portable oxygen in CAO

Test: A 6-min walking distance with visual analogue scales of breathlessness at rest before, and immediately after, each walk.

Walk

order: (1) Practice-discard results

(2) No cylinder

(3) Portable cylinder of compressed air, $4 \mathrm{l} / \mathrm{min}$

(4) Portable cylinder of compressed oxygen, $41 / \mathrm{min}$

Result: Positive if the distance or post-walk VAS of (4) are $>10 \%$ better than (2) and (3)

for only 60-90 min; both systems are cumbersome and equally heavy. Since few patients actually walk for as long as 90 min a day the portable cylinder is more convenient. The technology exists to make lightweight cylinders of polymer fibre which would allow considerable savings in weight and size. This would radically improve the convenience of portable oxygen and allow many more to benefit. Other advances suggested include the use of a small transtracheal cannula to deliver lower volumes of oxygen to the lungs in a way which need cause the patient no social embarrassment.

\section{Drug treatment of breathlessness}

The idea of treating the symptom of breathlessness itself, as opposed to its source, is not new. Morphine was given to relieve the breathlessness of asthma, pneumothorax and emphysema as well as that due to pulmonary oedema during the last century and probably for many years before. Attempts have been made to induce a hypothyroid state in order to improve breathlessness by reducing metabolic demand for oxygen. However, only recently have drugs been properly assessed for their effect on breathlessness.

Diazepam and promethazine. An important preliminary study by Guz's group (Mitchell-Heggs et al., 1980 ) indicated that diazepam might produce symptomatic relief of breathlessness and improvement in exercise tolerance in pink and puffing patients, without altering resting arterial blood gas tensions. Stark et al. (1981) then showed a slight reduction in breathlessness as measured by VAS following promethazine in normal subjects, although there was no change with diazepam.

These two drugs were, therefore, compared with placebo by Woodcock, Gross and Geddes (1981b) in 18 pink puffers with CAO in a 6-week outpatient study. Diazepam, $25 \mathrm{mg}$ daily, did not improve breathlessness or exercise tolerance but there was a small and significant improvement with promethazine both in the 12-min walking distance and VAS of breathlessness during exercise. Side effects were unacceptable with diazepam and, although drowsi $\frac{3}{\mathrm{D}}$ ness occurred with promethazine, this was no? intolerable. This study provided some encourage ment for the approach of treating breathlessness with drugs, but did not come up with a practical therapyo

The improvement shown was only slight and dif not represent an appreciable benefit to the patientse Furthermore, interpretation of this study is difficul since promethazine has many pharmacological pro응 perties and might have produced a small change inis lung or cardiac function.

Opiates. This group of drugs alleviate distress frome many unpleasant sensations but also have effects om ventilation which in theory might be helpful. These. properties are summarized in Table 4 . The potentiag disadvantages of opiates are many but in particulak the risks of addiction and dangerous ventilatory depression are paramount.

TABLE 4. Ventilatory properties of morphine (Weil et al., 1975, Kryger et al., 1976; Santiago et al., 1979)

(1) Resting ventilation reduced.

(2) Ventilatory response to hypoxia reduced.

(3) Ventilatory response to hypercapnia reduced.

(4) Oxygen consumption at rest and exercise reduced

(5) Response to inspiratory flow resistance reduced.

In an acute laboratory study a single dose of̆ dihydrocodeine (1 $\mathrm{mg} / \mathrm{kg}$ orally) was shown t\& reduce breathlessness and increase exercise tolerance in patients with severe airflow obstruction (Wood 3 cock et al., 1981). These changes were associated with a reduction in oxygen consumption and $\dot{\mathrm{V}}_{\mathrm{E}}$ for a giver amount of exercise. An initial attempt to exploit this improvement for chonic outpatient use was unsuc 3 . cessful with relatively high doses of dihydrocodeine (90-180 mg daily) due to unacceptably severe and frequent side effects (Woodcock, Johnson and Geddes, 1982). More encouraging results were ob३ tained when dihydrocodeine, $15 \mathrm{mg}$, was taken $30-45$ min before exercise as required, up to three times daily (Johnson, Woodcock and Geddes, 1983). Using this regimen a group of patients with CAO showed an improvement in breathlessness and mobilityo without experiencing any adverse effects. DihydrocoN deine may therefore provide worthwhile benefit tou some patients although the long-term value and safety of this form of treatment is not known.

Other opiates have not been fully assessed. $\mathrm{Co}$ deine had no effect on breathlessness in normal subjects, while buprenorphine in patients with interstitial lung disease provided no consistent benefit ano 
many patients became nauseated (unpublished). Clearly further studies are needed to confirm the reports using dihydrocodeine and perhaps to extend them to include other opiates, before this form of therapy can be widely recommended.

\section{Exercise training}

There are many studies (Pierce et al., 1964; Bass, Whitcomb and Foreman, 1970; Brundin, 1974; McGavin et al., 1977; Cockcroft, Saunders and Berry, 1981) which have shown that a programme of regular exercise improves the well-being and walking ability of patients with CAO. Various different forms of exercise have been used including simple stair climbing at home, treadmill exercise in a laboratory, and cycling, rowing or swimming in a gymnasium. The findings are consistent and show a subjective improvement often accompanied by an improved walking performance while lung function tests and maximum oxygen uptake are unchanged. These results imply an improvement in the efficiency of walking, such as an increase in stride length and motivation without any fundamental change in cardiorespiratory physiology.

Most of these studies have not included a control group and so critical analysis of the value of exercise programmes is difficult. This weakness is clearly very important in patients whose exercise tolerance is closely linked to pyschological factors and in whom placebo effects are likely to be important.

The study by Cockcroft, Saunders and Berry (1981) included a control group who were told that exercises might help but were given no special advice or facilities. The treatment group underwent graduated exercise training for 6 weeks by cycle, rowing machines, swimming and walking. Both groups were assessed every 2 months and after the first 4 months the control patients then underwent the same exercise training. This treatment design gives some measure of any initial placebo effect in the control group as well as allowing an estimate of the value of the training itself.

The results are summarized in Fig. 4 which shows a definite placebo effect as well as a significant improvement attributable to the exercise training alone. The training-related improvement was sustained for at least $\mathbf{4}$ months.

Should all patients who are disabled by CAO undergo exercise training and if so in what way? The simple answer must be that these patients should be encouraged to take regular exercise inside and outside the home and to push themselves to the limit of their breathlessness from time to time. If this advice is followed regularly then it is doubtful whether a gymnasium has very much extra to offer in purely physical terms; however the social and psy-

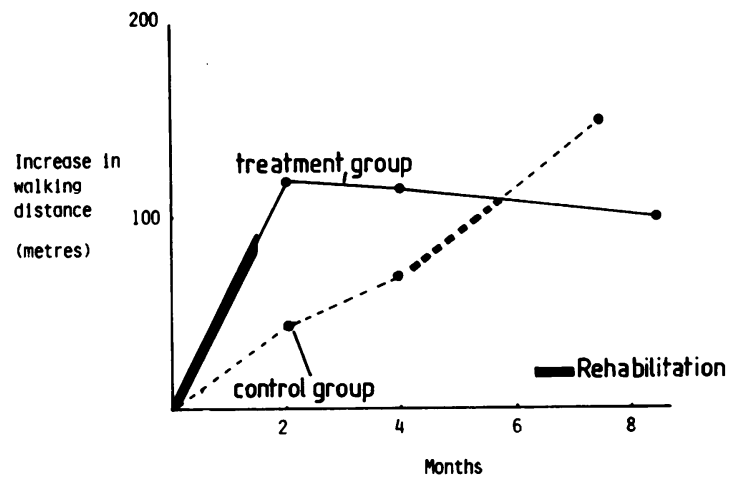

FIG. 4. Controlled trial of rehabilitation in chronic respiratory disability (Cockcroft et al., 1981).

chological affects of attending a centre for group activities of any sort will be an undoubted additional help to these patients.

\section{Conclusions}

Many patients with CAO remain severely disabled in spite of optimum medical treatment aimed at improving lung function. In these patients the value of oxygen, drugs for breathlessness and exercise training should be considered and when possible formally assessed as even a small improvement in walking performance may give surprisingly large benefits in quality of life. Since psychological factors are so important, the attitude of the physician and the psychological benefits of any attempt to help the patient's disability are in themselves as important as the treatment itself. The most depressing thing for any patient to hear is ' $I$ am afraid there is nothing we can do'. This is certainly not true.

\section{References}

Bass, H., Whitcomb, J.F. \& Foreman, R. (1970) Exercise training: therapy for patients with chronic obstructive pulmonary disease. Chest, 57, 116.

BOND, A. \& LADER, M. (1974) The use of visual analogue scales in rating subjective feelings. British Journal of Medical Psychology, 47, 211 .

Bradley, B.L., Garner, A.E., Billiu, D., Mestas, J.M. \& FORMAN, J. (1978) Oxygen assisted exercise in chronic obstructive lung disease. American Review of Respiratory Diseases, 118, 239.

BRUNDIN, A. (1974) Physical training in severe chronic obstructive lung disease parts I and II. Scandinavian Journal of Respiratory Diseases, 55, 25, 37.

Butland, R.J.A., Pang, J.A., Gross, E.R., Woodcock, A.A. \& GEDDES, D.M. (1982) Two, six and twelve minute walks compared. British Medical Journal, 284, 1607.

COCKCROFT, A.E., SAUnDers, M.J., BERRY, G. (1981) Randomised controlled trial of rehabilitation in chronic respiratory disability. Thorax, 36, 200.

CoTES, J.E. \& Gilson, J.C. (1956) Effects of oxygen on exercise ability in chronic respiratory insufficiency. Lancet, i, 872. 
Durwin, J.G.V.A. \& PASSMORE, R. (1967) Energy, work and leisure. Heinemann, London.

Fletcher, C.M., Elmes, P.C., Fairbairn, A.S. \& Wood, C.H. (1959) The significance of respiratory symptoms and the diagnosis of chronic bronchitis in a working population. British Medical Journal, 2, 257.

GUZ, A. (1977) Respiratory sensations in man. British Medical Bulletin, 3, 175.

GuZ, A., Adams, L., Minty, K. \& Murphy, K. (1981) Breathlessness and the ventilatory drives of exercise, hypercapnia and hypoxia. Clinical Science, 60, 17.

HOWELL, J.B.L. (1966) Breathlessness. Blackwell Oxford 1966.

JoHnson, M., WoodCocK, A.A. \& GedDES, D.M. (1983) Dihydrocodeine for breathlessness in pink puffers. British Medical Journal, 286, 675.

Kryger, M.H., Yacoub, D., Dosman, J., Macklam, P.T. \& ANTHONISEN, N.R. (1976) Effect of meperidine on occlusion pressure responses to hypercapnia and hypoxia with and without external inspiratory resistance. American Review of Respiratory Diseases, 114, 333.

LeggetT, R.J.E. \& Flenley, D.C. (1977) Portable oxygen and exercise tolerance in patients with chronic hypoxic cor pulmonale. British Medical Journal, 2, 84.

LiLbKeR, E.J., Kormick, A. \& LeRner, L. (1975) Portable oxygen in chronic obstructive lung disease with hypoxaemia and cor pulmonale. Chest, 68, 236.

McGavin, C.R., ARTvinli, M., NaOe, H. \& Mchardy, G.J.R. (1978) Dyspnoe, disability and distance walked: comparison of estimates of exercise performance in respiratory disease. British Medical Journal, 2, 241.

McGaVin, C.R., GuPTA, S.P., LlOYD, E.L. \& MCHARDY, G.J.R. (1977) Physical rehabilitation for chronic bronchitis: results of a controlled trial of exercises in the home. Thorax, 32, 307.

MCGavin, C.R., GuPTA, S.P. \& MCHARDY, G.J.R. (1976) Twelve minute walking test for assessing disability in chronic bronchitis. British Medical Journal, 2, 822.

Mitchell-Heggs, P., MurPhy, P., Minty, K. \& GuZ, A. (1980) Diazepam in the treatment of dyspnoea in the pink puffer syndrome. Quarterly Journal of Medicine, 49, 9.
Pierce, A.K., Paez, N. \& Miller, W.F. (1965) Exercise training with the aid of portable oxygen supply in patients with emphys sema. American Review of Respiratory Diseases, 91, 653.

Pierce, A.K., TAYLOR, H.F., ARCHER, R.K. \& Miller, W.F. (1964) Responses to exercise training in patients with emphysema. Archives of Internal Medicine, 113, 28.

SPIRo, S.G. (1977) Exercise testing in clinical medicine. British Journal of Diseases of the Chest, 71, 145.

Raimond, A.C., Edwards, R.H.T. \& Denison, D.M. (1980 Exercise tolerance breathing a low density gas mixture, 35\% oxygen and air in patients with chronic obstructive bronchitis Clinical Science, 39, 675.

Royal College of Physicians: College Committee of Thoracien Physicians (1981) Disabling chest disease: prevention and care Journal of the Royal College of Physicians, 15, 69.

SANTIAGo, T.V., JohnSon, J., RILEY, D.J. et. al. (1979) Effects of morphine on ventilatory response to exercise. Journal of Applied Physiology, 47, 112.

StaRK, R.D., Gambles, S.A. \& Lewis, J.A. (1981) Methods tহ assess breathlessness in healthy subjects. Clinical Science, 61, 429

WeIL, J.V., MCCullough, R.E., KLINE, J.S. \& SoDAL, I.E. (1975) DimiNished ventilatory response to hypoxia and hypercapniळ after morphine in normal man. New England Journal of Medicine 292, 1103.

WooDCoCK, A.A. (1982) Breathlessness in man: measurement and. modification. M.D. Thesis, University of Manchester.

WoodCocK, A.A., Gross, E.R. \& GEDDES, D.M. (1981a) Oxygen relieves breathlessness in pink puffers. Lancet, i, 907.

Woodcock, A.A., Gross, E.R. \& GedDES, D.M. (1981b) The drugtreatment of breathlessness: contrasting effects of diazepam and promethazine in the 'Pink Puffer' syndrome. British MedicaI Journal, 2, 343.

Woodcock, A.A., Gross, E.R., Gellert, A., Shah, S., JohnsonM. \& GEDDES, D.M. (1981) Breathlessness and exercise toler ficeo in subjects with airways obstruction and normal blood gases.ghe effects of dihydrocodeine, alcohol and caffeine. New Engtand Journal of Medicine, 305, 1611.

WoodCock, A.A., Johnson, M.A. \& GedDES, D.M. (1982 Breathlessness, alcohol and opiates. New England Journal of Medicine, 306, 1363. 